\title{
DISCIPLINAS E INTEGRAÇÃO CURRICULAR: HISTÓRIA E POLÍTICAS*
}

Maria InÊS Marcondes*

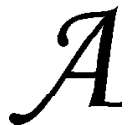

coletânea de textos organizada pelas professoras Alice Casimiro Lopes e Elizabeth Macedo reúne artigos elaborados por autores brasileiros da Universidade Federal de Minas Gerais (UFMG), da Universidade do Estado do Rio de Janeiro (UERJ) e da Universidade Federal do Rio de Janeiro (UFRJ). Inclui também a contribuição latinoamericana representada pela Argentina, Universidade de Buenos Aires, e européia, representada pelas contribuiçôes portuguesa da Universidade do Minho e francesa do Centro de Pesquisas Históricas (CNRS) e da Escola Superior de Altos Estudos em Ciências Sociais (Paris).

As organizadoras são reconhecidas pesquisadoras do campo do currículo e professoras em cursos de Graduação e Pós-Graduação na UFRJ e na UERJ, respectivamente. São também membros do Grupo de Trabalho de Currículo da Associação Nacional de Pós-Graduação e Pesquisa em Educação (ANPED).

Trata-se de uma coletânea composta por 8 artigos que têm em comum o foco no "conhecimento escolar" e sua organização nas políticas educacionais e no cotidiano das salas de aula. A intenção da obra é problematizar a relação entre integração curricular e disciplinas escolares com base na história e na política.

Os autores dos textos discutem o conhecimento escolar organizado em disciplinas (vistas ainda como indispensáveis instrumentos de sistematização de saberes e habilidades), mas não se restringindo mais aos limites disciplinares. Analisam o discurso da integração curricular

Resenha do livro Disciplinas e integração curricular: história e políticas, organizado por Alice Casimiro Lopes e Elizabeth Macedo (Rio de Janeiro: DP\&A, 2002).

** Professora do Departamento de Educação da Pontifícia Universidade Católica do Rio de Janeiro (PUC-RIO). 
que está sendo proposto e justificado por mudanças dos processos de trabalho e de organização do conhecimento no mundo globalizado. Destacam que a possível identificação nas propostas curriculares de expressões comuns àquelas utilizadas em outros momentos históricos do passado não é garantia de que os mesmos sentidos e significados se reproduzam, nem que estejam sendo perseguidas as mesmas finalidades educacionais.

A partir disso, faz-se urgente a interpretação dos discursos das atuais propostas curriculares oficiais, levando em conta a especificidade de cada um deles, assim como sua contextualização política, econômica, social e cultural. Fazer essa interpretação é uma das tarefas a que os autores dos artigos se propóem.

Trabalhar com a História do Currículo é reconstruir a história a partir de múltiplas versões, analisar documentos, estabelecendo relações e correlações no sentido de reconstruir uma rede de significados. Ao fazer essa reconstrução os autores enfrentam a tensão entre aspectos macro-sociais e as dimensões micro-referentes instituições e as salas de aula onde o currículo se materializa. Se reduzirmos a análise a um desses aspectos, corremos o risco de minimizar a complexidade do fazer curricular, defendem os autores. Reler cada um dos documentos para reconstruir o cotidiano curricular não é tarefa fácil, pois ele se apresenta complexo, difuso, difícil de captar e desvelar o que está encoberto.

A História do Currículo possibilita acompanhar a natureza das mudanças curriculares, compreendendo a gênese e o desenvolvimento de determinadas categorias que hoje estão presentes, muitas das vezes, com outros significados. Analisar políticas curriculares, tendo como pano de fundo a história do currículo, é um dos objetivos desempenhados com sucesso pela coletânea apresentada.

Com base em nossa leitura e na introdução da obra feita pelas suas organizadoras, Lopes \& Macedo, fazemos um breve resumo dos textos apresentados:

$\mathrm{O}$ artigo de Luciano Mendes de Faria Filho, "Escolarização, culturas e práticas escolares no Brasil: elementos teórico-metodológicos", defende novas perspectivas para a pesquisa sobre a escola em História da Educação. O fenômeno da escolarização é estudado pelo autor: de uma sociedade sem escolas no início do século XIX ao início do XXI com a quase totalidade de nossas crianças na escola. Tempos, espaços, sujeitos, conhecimentos e práticas escolares são focalizados como elementos-chave dessa análise. Ao analisar a cultura escolar o autor mostra o surgimento 
no currículo brasileiro da seriação e da organização disciplinar e quais as suas conseqüências para a escolarização e, dessa, para a cultura social mais ampla. De acordo com o autor, "A escola vai-se constituindo, assim, não apenas no locus privilegiado da cultura e da formação humana, mas também como um grande mercado de trabalho e de consumo de inúmeros produtos da cada vez mais complexa e poderosa indústria editorial, entre outras" (p. 35).

$\mathrm{O}$ artigo de Dominique Juliá, "Disciplinas escolares: objetivos, ensino e apropriação", por sua vez, discute a pesquisa em história das disciplinas escolares, argumentando que esse campo de estudos deve levar em conta os objetivos associados não apenas às referidas disciplinas, mas também às práticas reais de ensino e à apropriação dos conteúdos por parte dos alunos. O autor apresenta e discute os cuidados metodológicos que os historiadores do currículo devem ter ao substituir as análises macroscópicas pelo estudo dos funcionamentos internos específicos de cada escola. Essas duas instâncias vêm se complementar, oferecendo ao pesquisador um quadro de análise mais completo e abrangente. $\mathrm{O}$ autor conclui dizendo que

resulta essencial relembrar que toda a história das disciplinas escolares deve, em um mesmo movimento, considerar as finalidades óbvias ou implícitas buscadas, os conteúdos de ensino e a apropriação realizada pelos alunos, tal como pode ser medida por meio de trabalhos e exercícios. Há uma interação constante entre esses três pólos que concorrem na constituição de uma disciplina e estaríamos incorrendo diretamente em graves erros se quiséssemos ignorar ou negligenciar qualquer um deles. (P. 51)

Em seu artigo Dominique Juliá abarca esses três pólos.

As organizadoras da obra, Alice Casimiro Lopes e Elizabeth Macedo, são também autoras do artigo "A estabilidade do currículo disciplinar: o caso das ciências". Nele, levantam a hipótese de que, mesmo em currículos transversais (em que a matriz do conhecimento não é disciplinar), a força dos processos de administração curricular acabaria acarretando a organização de disciplinas com finalidade de controle do trabalho docente e/ou para controle das atividades dos alunos. As autoras analisam o caso da disciplina ciências, em virtude de se tratar do exemplo de uma dessas tentativas de produzir uma integração pela via disciplinar. No artigo recorrem aos trabalhos de Ivor Goodson e Boaventura de Souza Santos, para argumentar que a disciplina escolar é diferente da disciplina científica. 
Silvina Givirtz et al., no artigo intitulado "A politização do currículo de ciências nas escolas argentinas (1870-1950)", argumentam que os conteúdos de ensino em ciências foram selecionados e organizados em disciplinas de modo a buscar resolver conflitos ideológicos. No sentido de sustentar sua argumentação, apresentam dois estudos sobre as formas como determinados assuntos são introduzidos e posicionados no currículo, buscando identificar os componentes ideológicos dessa seleção e organização. As autoras tratam especificamente dos campos da astronomia e da cosmografia e das teorias da evolução. Concluem os autores que "existem relaçôes complexas entre as ciências naturais, a instituição escolar e a política" (p. 9).

O artigo de Elizabeth Macedo, "Currículo e competência", analisa como a utilização da noção de competências vem respondendo, na teorização curricular, a novas formas de organização do saber e do trabalho na sociedade comtemporânea. A partir da análise dos documentos curriculares para a educação básica a autora identifica três inspirações principais: a tradição francesa de competência, o comportamentalismo americano das teorias de competência e as abordagens de conhecimento e mercado, que vêm dando destaque a saberes não-disciplinares. Compreendendo as políticas da elaboração curricular "como híbridos de muitas tradições em conflito", a autora defende a "necessidade de se buscar entender como se configuram os mecanismos de poder e quais as finalidades sociais de transição do currículo disciplinar para um currículo orientado por competências" (p. 9). A autora conclui o seu artigo defendendo que a centralidade na noção de competência, ainda que se utilizando variados elementos dos discursos educacionais construídos ao longo do último século e se apropriando de reivindicaçôes do próprio campo, está alicerçada nas demandas postas à escola por um novo perfil do mercado produtivo (p. 141). O tema é instigante e a análise da autora é de extrema atualidade.

No artigo de Alice Casimiro Lopes, "Parâmetros curriculares para o ensino médio: quando a integração perde o seu potencial crítico", o foco volta-se para as atuais políticas curriculares para o ensino médio. A autora defende que o potencial crítico do discurso sobre currículo integrado encontra-se recontextualizado nos Parâmetros Curriculares Nacionais do Ensino Médio (PCNEM) a partir de processos de deslocalização de suas matrizes teóricas originais e de relocalização por hibridização, especialmente, com os discursos derivados das matrizes dos eficientistas sociais (o currículo por 
competências), associados a princípios integradores completamente distanciados de uma perspectiva crítica (p. 148).

No artigo de José Augusto Pacheco, "Área de projecto: uma componente curricular não-disciplinar”, é analisada a recente reforma curricular portuguesa do ensino secundário, no que se refere às formas de organização curricular. O autor trata especificamente da área do projeto, que privilegia a interação entre escola e realidade e propõe a inversão da lógica curricular da transmissão para o questionamento. Esse artigo tem especial importância para nós, no Brasil, dado que os projetos têm sido propostos nas mais recentes reformas curriculares.

Finalizando a coletânea, o interessante artigo de Alfredo VeigaNeto, "Espaço e currículo", focaliza algumas questões relativas à contribuiçãao do currículo para a constituição do sujeito moderno. $\mathrm{Na}$ análise do autor, "é também pelo currículo que aprendemos a conferir sentidos e fazer uso do espaço e, de maneira obrigatoriamente imbricado, do tempo" (p. 11). Segue o autor defendendo a idéia de que "a integração e a transversalidade devem ser entendidas como invençôes curriculares que representam novas configurações” (p. 11). O tema é abordado com originalidade.

Os estudos históricos sobre currículo transformam nosso foco de atenção colocando novos questionamentos e nos instigando a continuar a pesquisa, colaborando no desenvolvimento de outros estudos, na análise de propostas curriculares e na constante e necessária reflexão sobre as práticas escolares em diferentes níveis e contextos.

Entre os méritos da obra destacamos, em primeiro lugar, a utilização de uma linguagem clara, portanto de fácil compreensão, mesmo para os não iniciados no campo do estudo e da pesquisa sobre currículo. Em segundo lugar, o desenvolvimento de uma análise profunda utilizando autores consagrados no campo da história e da política. Dentre eles, destacamos a referência ao autor clássico na história do currículo, Ivor Goodson, que tem tentado, com sucesso, construir um arcabouço teórico para o estudo da história das disciplinas. Seu trabalho desvela o processo pelo qual determinadas áreas do conhecimento são transformadas em disciplinas escolares. Finalmente, destacamos a importante e necessária reflexão sobre temas da atualidade no contexto atual de reformas. Nosso país vive hoje em processo de implantação de várias reformas curriculares e elas têm sido apresentadas como elementos fundamentais para o alcance da melhoria da qualidade da educação dada pelos sistemas de ensino. 
De um modo geral elas têm sido concebidas tendo como base a visão de especialistas e de consultores internacionais, deixando em segundo plano a experiência dos seus reais implementadores - os professores dos diferentes níveis de ensino. As dificuldades de implantação e até mesmo de entendimento dessas novas propostas nos fazem analisar com maior cuidado o papel e a importância do currículo, seu discurso e sua prática em nossa realidade. Ao buscar subsídios teóricos para a análise desse quadro encontramos na coletânea de Lopes \& Macedo temáticas como "parâmetros", "competências" e "projetos" analisadas nos artigos com base em autores de currículo vinculados aos paradigmas críticos e pós-críticos.

Pelas razões acima descritas, recomendo enfaticamente o livro por possibilitar um entendimento mais profundo dessas reformas, suas conseqüências na prática diária de nossas escolas e na busca de alternativas na superação dos impasses apresentados. O livro traz importantes subsídios para essa tarefa.

Por se tratar de obra de conteúdo crítico, apresenta-se como leitura indispensável para pesquisadores da área, professores da disciplina Currículo, estudantes de Pós-Graduação e de Graduação. Lembrando que a história do currículo é parte da história da educação, recomendamos também o livro para professores e pesquisadores do campo. Sua leitura será certamente enriquecedora para sua reflexóes e análises. 